\title{
Solvent Extraction Behavior of Silver with the Secondary Phenylamide Derivative of the Trident Molecule
}

\author{
Yuki UEDA, ${ }^{1}$ Shintaro MORISADA, ${ }^{1}$ Hidetaka KAWAKITA ${ }^{1}$ and Keisuke OHTO ${ }^{1}$ * \\ ${ }^{1}$ Department of Chemistry and Applied Chemistry, Saga University, 1-Honjo, Saga 840-8502, Japan \\ (Received January 7, 2013; Accepted February 1, 2013)
}

\begin{abstract}
The secondary phenylamide derivative of a trident molecule has been prepared as a novel solvent extraction reagent to investigate and to compare its extraction ability with its corresponding monopodal analogues, for the extraction of precious and base metals in nitric acid solution. The extraction ability of the trident extractant was superior to that of the monopodal analogue. The secondary phenylamide type of trident molecule exhibited extractive selectivity for silver and divalent palladium over other precious metals and base metals in nitric acid solution. The extraction mechanism of silver with the trident extractant was determined by slope analysis and the peak shift of the FT-IR and ${ }^{1}$ H-NMR spectra of the extraction reagent before and after silver loading.
\end{abstract}

\section{Introduction}

Precious metals are indispensable metal elements in modern industries, particularly as exhaust gas catalysts, in petrochemical and bio fuel processing [1-3]. However, the natural abundance of precious metals is extremely small and they exist in limited areas. Therefore, it is necessary to establish thean efficient recovery process for precious metals. Hydrometallurgical processes have been applied to the separation of precious metals. Solvent extraction is one of the most important metal separation methods. For example it has been used in the Vale-INCO process [4]. However, conventional solvent extraction reagents for precious metals are still ineffective and unsatisfactory for their mutual separation, consequently it is necessary to prepare new more effective and selective solvent extraction reagent for precious metals.

Various types of extraction reagents based on macrocycles and pseudomacrocycles, such as calixarenes [5-15] and tripodal alkyltrimethylol compounds as "trident" molecule [16-18] have been prepared for metal separation by our group. A trident is a three-pronged spear as used for fishing for target 
fishes. The tripodal molecules have been applied to a variety of fields such as transmembrane transfer [19], metal complex catalysts [20-23] and anion receptors [24, 25] based on their structural specificity.

The trident amino molecule employed as a precursor in the present work provides the following characteristics:

1. possessing three primary amino groups for chemical modification to metal coordinating groups,

2. a relatively narrow coordination site for size recognition,

3. high coordination ability due to the chelating and preorganized effects.

In our previous work, 25, 26, 27, 28-tetrakis ( $N, N$-diethylamidecarbonylmethoxy)-5, 11, 17, 23-tetrakis(1, 1, 3, 3-tetramethylbutyl)calix[4]arene, was prepared to investigate the extraction behavior for silver and divalent palladium from highly acidic solutions into chloroform [26]. The amide compounds have three advantages in that they can be completely incinerated at the end of the process as they only contain atoms of hydrogen, carbon, nitrogen and oxygen [27], they are poorly soluble in the aqueous phase because of the neutral ligand and, moreover, they have a strong coordination ability throught the high charge density carbonyl oxygen atom [28, 29].

In the present work, amide type derivatives of the trident molecule together with the corresponding monopodal analogue have been synthesized to investigate the solvent extraction of some precious and base metal ions from nitrate media.

\section{Experimental}

\subsection{Reagents}

1,1,1-Tris(aminomethyl)-9-decene $\left({ }^{8}\right.$ Nonenyl $\left.\{3\} \mathrm{CH}_{2} \mathrm{NH}_{2}\right),{ }^{8}$ Nonenyl $\{3\} \mathrm{CH}_{2} \mathrm{NH}_{2}$ was prepared in a manner similar to that described in a previous paper[30]. Chemical structures and abbreviations of the extraction reagents used in the present study are shown in Figure 1. Synthetic schemes of the extraction reagents are shown in Figure 2.

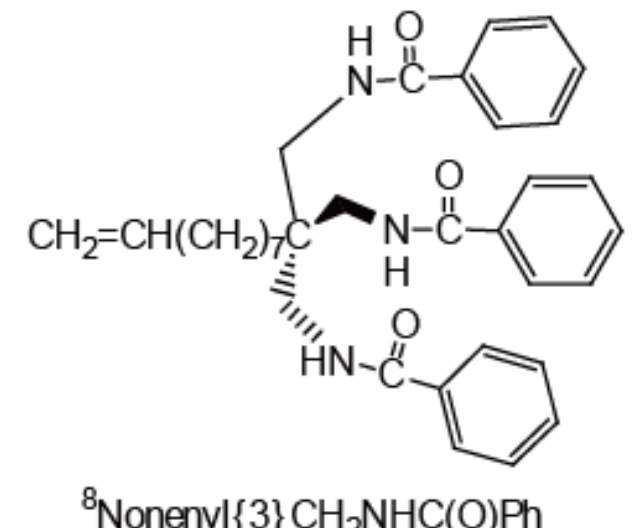

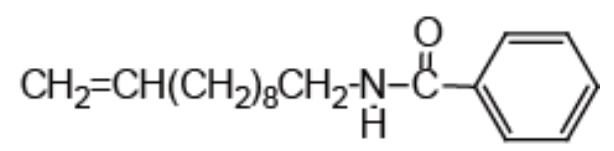

${ }^{8} \mathrm{Nonenyl}\{1\} \mathrm{CH}_{2} \mathrm{NHC}(\mathrm{O}) \mathrm{Ph}$

Figure 1. Chemical structures and abbreviations of the trident molecule and the corresponding monopodal analogue used in the present study. 


\section{$\underline{\text { 1,1,1-Tris(benzoamidemethyl)-9-decene }\left({ }^{8} \mathrm{Nonenyl}\{3\} \mathrm{CH}_{2}\right.} \underline{\underline{\mathrm{NHC}}(\mathrm{O}) \mathrm{NHPh})}$}

${ }^{8}$ Nonenyl $\{3\} \mathrm{CH}_{2} \mathrm{NH}_{2}(3.50 \mathrm{~g}, 15.4 \mathrm{mmol})$ was added to $100 \mathrm{~cm}^{3}$ pyridine in an ice bath. Benzoyl chloride $(8.65 \mathrm{~g}, 61.6 \mathrm{mmol}, 4 e q)$ was slowly added to the mixture and stirred for $30 \mathrm{~min}$ at room temperature. Then, in an oil-bath, the mixture was stirred for $48 \mathrm{~h}$ at $333 \mathrm{~K}$. Then, distilled water $\left(25 \mathrm{~cm}^{3}\right)$ was added. The desired compound was extracted three times with chloroform, and the organic phase was washed three times, each with saturated sodium hydrogen carbonate solution $\left(30 \mathrm{~cm}^{3}\right)$ and distilled water $\left(30 \mathrm{~cm}^{3}\right)$. The solution was dried over anhydrous magnesium sulfate. After filtration, the solvent was evaporated to obtain $6.28 \mathrm{~g}(11.1 \mathrm{mmol})$ of a yellow oil. TLC $\left(\mathrm{SiO}_{2}\right.$, chloroform : methanol = 9:1) $R_{\mathrm{f}}=$ 0.57, ${ }^{1} \mathrm{H}-\mathrm{NMR}\left(300 \mathrm{MHz}, \mathrm{CDCl}_{3}, \mathrm{TMS}, 27^{\circ} \mathrm{C}\right), \delta 1.19-1.98\left(12 \mathrm{H}, \mathrm{m},\left(\mathbf{C H}_{\mathbf{2}}\right)_{\mathbf{6}}\right), 2.08\left(2 \mathrm{H}, \mathrm{m}, \mathrm{CH}-\mathbf{C H}_{2}\right)$, $3.36\left(6 \mathrm{H}, \mathrm{s}, \mathbf{C H}_{2}-\mathrm{NH}\right), 4.98\left(2 \mathrm{H}, \mathrm{t}, \mathbf{C H}_{2}=\mathrm{CH}\right), 5.82\left(1 \mathrm{H}, \mathrm{m}, \mathrm{CH}_{2}=\mathbf{C H}\right), 6.47\left(3 \mathrm{H}, \mathrm{s}, \mathrm{CH}_{2}-\mathbf{N H}\right), 7.52(9 \mathrm{H}, \mathrm{m}$, 2PhH + 3PhH), $8.01(6 \mathrm{H}, \mathrm{d}, \mathbf{1 P h H})$, and FT-IR $\left(v_{\mathrm{N}-\mathrm{H}}, 3342 \mathrm{~cm}^{-1}\right),\left(v_{\mathrm{Ph}-\mathrm{H}}, 3064 \mathrm{~cm}^{-1}\right),\left(v_{\mathrm{C}-\mathrm{H}}, 2891 \mathrm{~cm}^{-1}\right)$, $\left(v_{\mathrm{C}=\mathrm{O}}, 1651 \mathrm{~cm}^{-1}\right),\left(v_{\mathrm{C}=\mathrm{C}}, 909 \mathrm{~cm}^{-1}\right)$.

\section{$\underline{\text { 1-Benzoamide-10-undecene }\left({ }^{8} \mathrm{Nonenyl}\{1\} \mathrm{CH}_{2} \mathrm{NHC}(\mathrm{O}) \mathrm{NHPh}\right)}$}

This was prepared in a similar manner to $\left.{ }^{8} \mathrm{Nonenyl}_{\{3}\right\} \mathrm{CH}_{2} \mathrm{NHC}(\mathrm{O}) \mathrm{NHPh}$ from 1-amino-10-undecene. This produced a yellow oil $3.97 \mathrm{~g}(13.9 \mathrm{mmol}), \mathrm{TLC}\left(\mathrm{SiO}_{2}\right.$, chloroform : methanol = $9: 1) R_{\mathrm{f}}=0.60$, and ${ }^{1} \mathrm{H}-\mathrm{NMR}\left(300 \mathrm{MHz}, \mathrm{CDCl}_{3}, \mathrm{TMS}, 27^{\circ} \mathrm{C}\right), \delta 1.31\left(12 \mathrm{H}, \mathrm{t},\left(\mathbf{C H}_{2}\right)_{\mathbf{6}}\right), 1.61(2 \mathrm{H}, \mathrm{q}$, $\left.\left(\mathrm{CH}_{2}\right)_{6}-\mathbf{C H}_{2}\right), 2.04\left(2 \mathrm{H}, \mathrm{m}, \mathrm{CH}-\mathbf{C H}_{2}\right), 3.41\left(2 \mathrm{H}, \mathrm{q}, \mathbf{C H}_{2}-\mathrm{NH}\right), 4.99\left(2 \mathrm{H}, \mathrm{m}, \mathbf{C} \mathbf{H}_{2}=\mathrm{CH}\right), 5.82(1 \mathrm{H}, \mathrm{m}$, $\left.\mathrm{CH}_{2}=\mathbf{C H}\right), 6.42\left(1 \mathrm{H}, \mathrm{s}, \mathrm{CH}_{2}-\mathbf{N H}\right), 7.42(3 \mathrm{H}, \mathrm{m}, \mathbf{2} \mathbf{P h H}+\mathbf{3 P h H}), 7.77(2 \mathrm{H}, \mathrm{d}, \mathbf{1 P h H})$, and FT-IR $\left(v_{\mathrm{N}-\mathrm{H}}\right.$, $\left.3339 \mathrm{~cm}^{-1}\right),\left(v_{\mathrm{Ph}-\mathrm{H}}, 3064 \mathrm{~cm}^{-1}\right),\left(v_{\mathrm{C}-\mathrm{H}}, 2914 \mathrm{~cm}^{-1}\right),\left(v_{\mathrm{C}=\mathrm{O}}, 1636 \mathrm{~cm}^{-1}\right),\left(v_{\mathrm{C}=\mathrm{C}}, 911 \mathrm{~cm}^{-1}\right)$.<smiles>C=CCCC(CN)(CN)CN</smiles>

\section{1,1,1-Tris(aminomethyl)-9-decene M.W. $=227.39$}

benzoyl chloride M.W. $=140.57$<smiles>O=C(Cl)c1ccccc1</smiles>

Benzoyl chloride M.W. $=140.57$

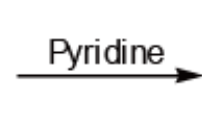<smiles>C=CCCCCNC(=O)c1ccccc1</smiles>

\section{1-Benzoamide-9-decene} M.W. $=285.36$

Figure 2. Synthetic schemes for the secondary phenylamide derivatives of the trident molecule and the corresponding monopodal analogue. 


\subsection{Extraction of metal ions}

Organic solutions were prepared by dissolving the trident extractant in analytical grade chloroform to a concentration of $5 \mathrm{mM}\left(\mathrm{M}=\mathrm{mol} \mathrm{dm}^{-3}\right)$. The concentration of the monopodal analogue was adjusted to be $15 \mathrm{mM}$ so that the concentration of the amide groups for the monopodal molecule is equal to that for the trident molecule. Aqueous solutions were prepared by dissolving each metal salt in nitric acid to the desired acid and metal concentrations. Equal volumes of both phases were mixed and vigorously shaken at $303 \mathrm{~K}$ for $24 \mathrm{~h}$. After phase separation, the metal concentrations in the aqueous phase were measured by ICP-AES (Shimadzu ICPS-8100).

\subsection{FT-IR spectroscopy}

Organic solutions were prepared by dissolving the extractant in analytical grade deuterated chloroform to the desired concentrations in order to create the same conditions as for section 2.4. Aqueous solutions were prepared by dissolving the metal salts in analytical grade nitric acid solution to the desired acid and metal concentrations. Equal volumes of both phases were mixed and vigorously shaken at $303 \mathrm{~K}$ for $24 \mathrm{~h}$. After phase separation, the spectra of the extraction reagent in the organic phase were quantitatively measured by the Nujol method using a FT-IR spectrophotometer (JASCO FT/IR-410). The metal concentrations in aqueous phase were measured by ICP-AES.

\subsection{Proton NMR study}

Organic solutions were prepared by dissolving the extractant in analytical grade deuterated chloroform to the desired concentrations. Aqueous solutions were prepared by dissolving the metal salt in analytical grade nitric acid solution to the desired acid and metal concentrations. Equal volumes of both phases were mixed and vigorously shaken at $303 \mathrm{~K}$ for $24 \mathrm{~h}$. After phase separation, the metal concentration in the aqueous phase was measured by ICP-AES and the spectra of the extraction reagent in the organic phase were measured using a ${ }^{1}$ H-NMR spectrophotometer (Jeol JNM-GX300).

\section{Results and Discussion}

\subsection{Extraction of silver}

The effects of nitric acid concentration on the distribution ratio of silver with the trident molecule and the monopodal analogue are shown in Figure 3. The distribution ratio is defined by equation (1) :

$$
D=\frac{[\text { Metal }]_{\text {org. }}}{[\text { Metal }]_{\text {aq. }}}
$$

where $[\text { Metal }]_{\text {org. }}$ and $[\text { Metal }]_{\text {aq. }}$ are the metal concentrations in the organic and aqueous phases, respectively. From the result, silver extraction with both extractants seems not to be dependent on the nitric acid concentration in the range 0.1 to $5.0 \mathrm{M}$. However, uncertain results for silver extraction have been similarly reported in our previous papers [18, 28]. Furthermore, it was already confirmed that silver distributed to chloroform in the absence of an extractant at over $5 \mathrm{M}$ nitric acid concentrations. The trident molecule exhibited higher extraction ability than the corresponding monopodal analogue due to the partial 
converging effect of the functional groups. Silver exists as a cationic species in nitrate media. The secondary phenylamide extraction reagent is a neutral molecule and extracts silver as a cation together with nitrate as a counter anion by a direct coordination mechanism.

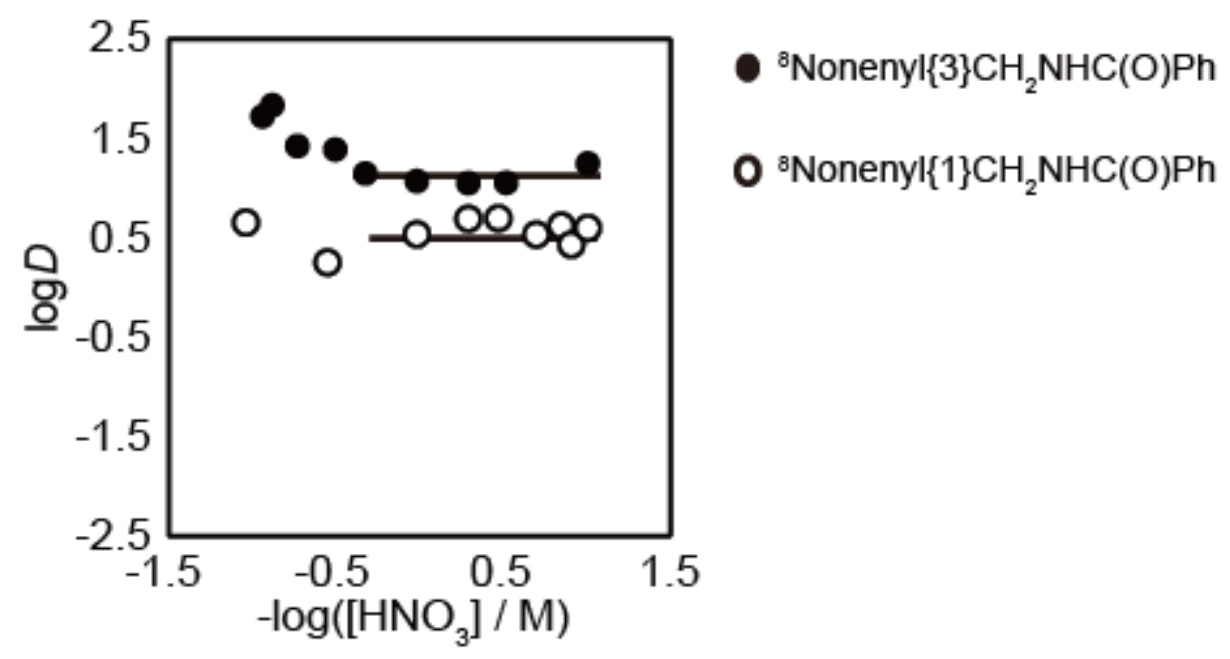

Figure 3. Effect of nitric acid concentration on the distribution ratio of silver with the trident extraction reagent and the corresponding monopodal analogue. $\left[\mathrm{Ag}^{+}\right]=0.1 \mathrm{mM}$, $\left[{ }^{8} \mathrm{Nonenyl}\{3\} \mathrm{CH}_{2} \mathrm{NHC}(\mathrm{O}) \mathrm{Ph}\right]=5.0$ $\mathrm{mM},\left[{ }^{8}\right.$ Nonenyl $\left.\{1\} \mathrm{CH}_{2} \mathrm{NHC}(\mathrm{O}) \mathrm{Ph}\right]=15 \mathrm{mM}$.

The effects of extractant concentration on the distribution ratio of silver with both secondary phenylamide type extractants are shown in Figure 4. In the case of the trident molecule, the experimental points lie on a straight line with a slope of 1 , on the other hand, in the case of the monopodal analogue, the points lie on a straight line with a slope of 2 . From these results, it is elucidated that the trident molecule forms a $1: 1$ (extractant : silver) complex with silver, while the monopodal analogue forms a $2: 1$ complex.

Althought no nitric acid dependency was observed, extraction equilibrium equations for both extractants are proposed as equations (2) and (3), respectively,

$$
\begin{aligned}
& {[\text { tExt. }]+\mathrm{Ag}^{+}+\mathrm{NO}_{3}^{-} \leftrightharpoons\left[\text { tExt. } \cdot \mathrm{Ag}^{+} \cdot \mathrm{NO}_{3}{ }^{-}\right]} \\
& 2[\text { mExt. }]+\mathrm{Ag}^{+}+\mathrm{NO}_{3}{ }^{-} \leftrightharpoons\left[2 \mathrm{mExt} \cdot \mathrm{Ag}^{+} \cdot \mathrm{NO}_{3}{ }^{-}\right]
\end{aligned}
$$

where tExt. and mExt. represent the trident and monopodal molecules, respectively. 


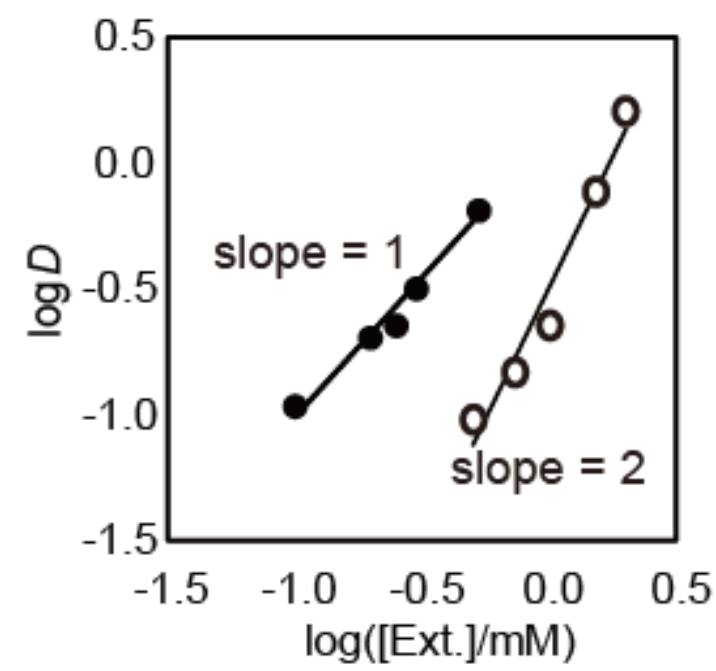

${ }^{8} \mathrm{Nonenyl}\{3\} \mathrm{CH}_{2} \mathrm{NHC}(\mathrm{O}) \mathrm{Ph}$

$0{ }^{8} \mathrm{Nonenyl}\{1\} \mathrm{CH}_{2} \mathrm{NHC}(\mathrm{O}) \mathrm{Ph}$

Figure 4. Effects of extraction reagent concentration on the distribution ratio of silver with both secondary phenylamide type extraction reagents. $\left[\mathrm{Ag}^{+}\right]=0.1 \mathrm{mM},\left[\mathrm{HNO}_{3}\right]=1.0 \mathrm{M}$.

\subsection{FT-IR spectroscopy}

To determine the coordination sites of the secondary phenyl amide trident molecule for the extraction of silver, a FT-IR spectrophotometric study was carried out. The FT-IR spectra of the secondary phenylamide trident molecule before and after silver loading in nitrate media are shown in Figure 5.

After silver loading, a new carbonyl group absorption peak carbonyl group was observed at 1524 $\mathrm{cm}^{-1}$. However the free carbonyl group absorption peak of free carbonyl group was also observed. This result showed that two types of amide groups existed in the trident molecule after complete silver loading. One is the free amide group, the other is the amide group directly coordinating to silver. Consequently, it was suggested that the three phenylamide groups directly coordinated to silver.

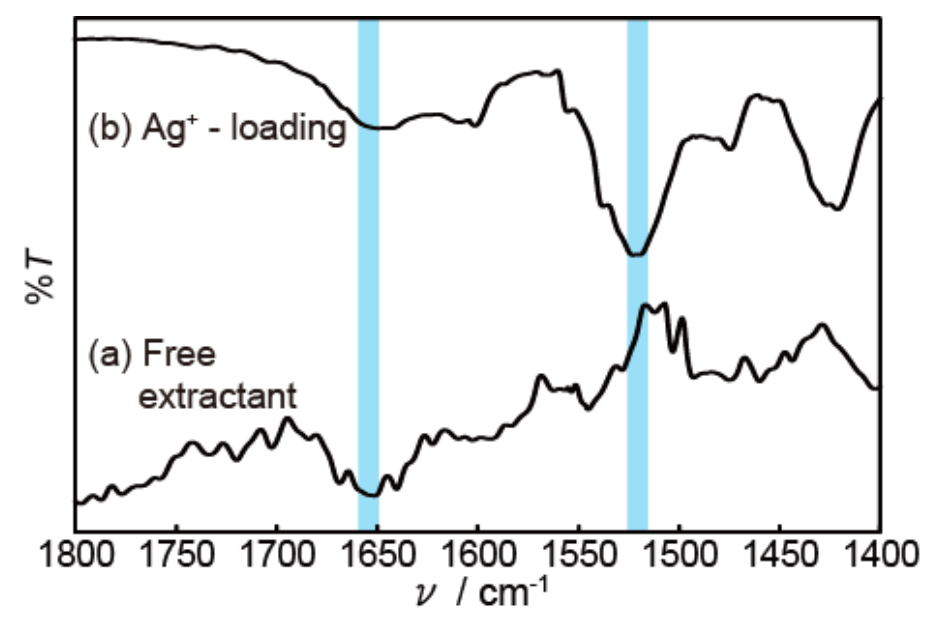

Figure 5. FT-IR spectra of the secondary phenyl amide type of trident extraction reagent (a) before and (b) after silver loading in nitrate media. $\left[\mathrm{Ag}^{+}\right]=2.0 \mathrm{mM}$, $\left[{ }^{8} \mathrm{Nonenyl}\{3\} \mathrm{CH}_{2} \mathrm{NHC}(\mathrm{O}) \mathrm{Ph}\right]=1.0 \mathrm{mM},\left[\mathrm{HNO}_{3}\right]=$ $1.0 \mathrm{M}$, [Aq. phase $]=10 \mathrm{~cm}^{3}$, [Org. phase $]=2.0 \mathrm{~cm}^{3}$. 


\subsection{Proton NMR study}

To elucidate the specific extraction mechanism of silver with the trident molecule, a ${ }^{1} \mathrm{H}-\mathrm{NMR}$ spectrophotometric study was carried out. The ${ }^{1} \mathrm{H}-\mathrm{NMR}$ spectra of the secondary phenylamide trident molecule before and after silver loading in nitric acid are shown in Figure 6.

The amide proton and the phenyl proton peak were observed at $6.47 \mathrm{ppm}$ and $7.52-8.01 \mathrm{ppm}$, respectively. A peak shift in the ${ }^{1} \mathrm{H}-\mathrm{NMR}$ spectra of ${ }^{8} \mathrm{Nonenyl}\{3\} \mathrm{CH}_{2} \mathrm{NHC}(\mathrm{O}) \mathrm{C}_{6} \mathrm{H}_{5}$ was not observed, although the same sample, which was measured using ICP-AES was completely loaded with silver. That is, silver was loaded on the extractant without any peak shift. In our previous work, when host molecules such as calixarene derivatives were structurally fixed by silver loading, peak shifts of the aryl protons were observed due to the shielding effect of the for $\pi$-electrons of the benzene rings [17, 18, 28]. Silver was extracted inside the extractant molecule and sufficiently surrounded by functional groups. The fact that no peak shift for the secondary amide protons was observed suggested that only the carbonyl oxygen atoms were involved silver loading. Because of this observation, it was suggested that the structure and the electronic state of trident molecule was not much changed before and after silver loading. Therefore, the recognition of the silver by the trident molecule was not inside but outside of the tripodal site. If silver recognition with the trident molecule was inside the tripodal site, the electronic state of the amide proton and the phenyl proton should be significantly changed. Consequently, silver recognition took place outside of the tripodal site, and a peak shift was not observed.

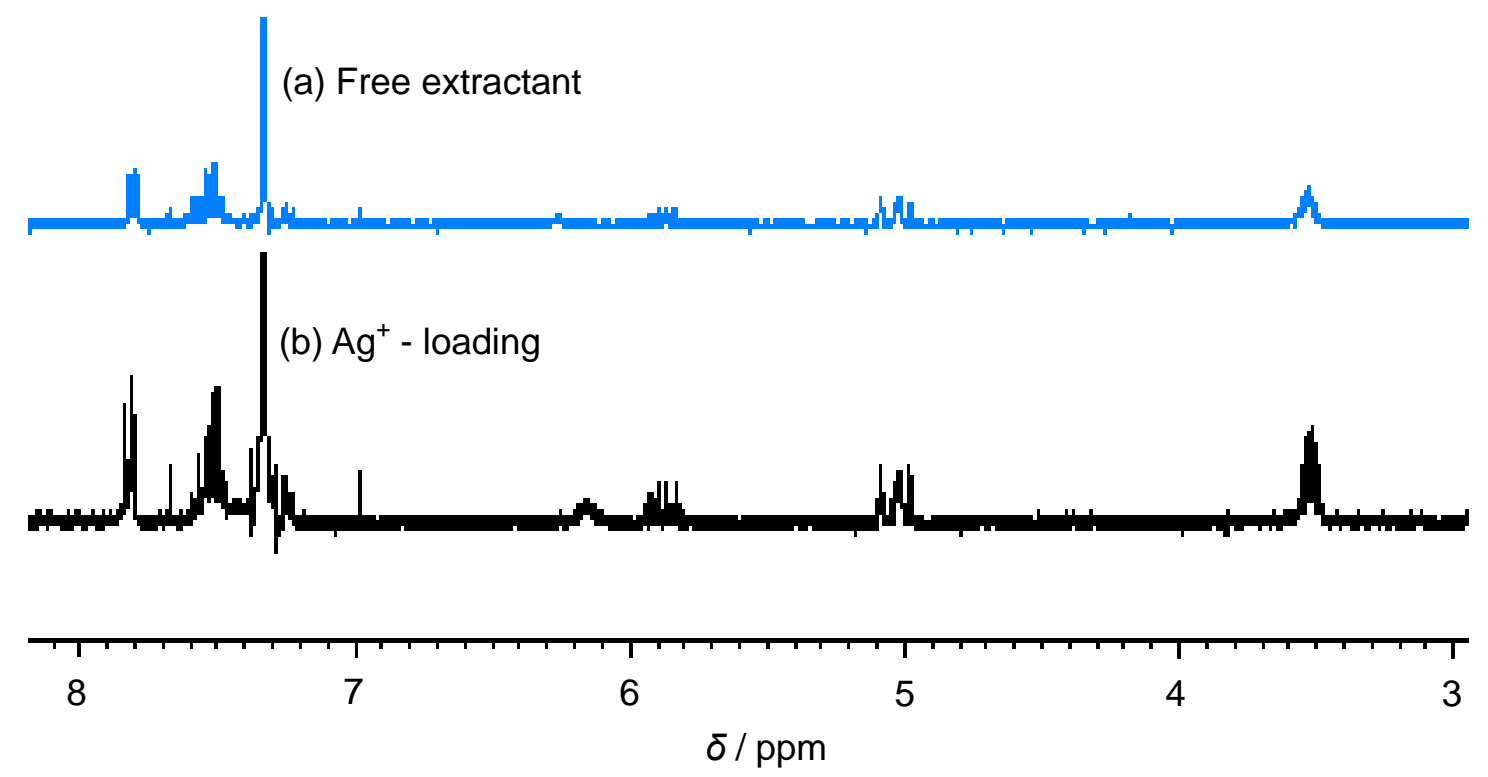

Figure $6 .{ }^{1} \mathrm{H}-\mathrm{NMR}$ spectra of the secondary phenylamide type of the trident extraction reagent (a) before and (b) after silver loading in nitrate media. $\left[\mathrm{Ag}^{+}\right]=2.0 \mathrm{mM}$, $\left[{ }^{8} \mathrm{Nonenyl}\{3\} \mathrm{CH}_{2} \mathrm{NHC}(\mathrm{O}) \mathrm{Ph}\right]=1.0 \mathrm{mM}$, $\left[\mathrm{HNO}_{3}\right]=1.0 \mathrm{M},[$ Aq. phase $]=10 \mathrm{~cm}^{3},[$ Org. phase $]=2.0 \mathrm{~cm}^{3}$. 


\subsection{Extraction mechanism of silver with ${ }^{8} \mathrm{Nonenyl}\{3\} \mathrm{CH}_{2} \mathrm{NHC}(\mathrm{O}) \mathrm{C}_{6} \mathrm{H}_{5}$ and ${ }^{8}$ Nonenyl $\{1\} \mathrm{CH}_{2} \mathrm{NHC}(\mathrm{O}) \mathrm{C}_{6} \mathrm{H}_{5}$}

Silver extraction models with the secondary phenylamide trident and the monopodal molecules in nitric acid solution developed from the above results are proposed in Figures 7 (a) and (b). In the case of the phenylamide type of trident molecule, the extraction reagent molecule extracts the silver as a cation together with a counter anion by a direct coordination mechanism. There are several reasons why, even though the molecule is a tridentate ligand, the extraction model of the trident molecule has been proposed as a bidentate ligand. First, the stoichiometry of the phenylamide type of the monopodal molecule is $2: 1$ (extractant : silver). This result suggested that silver is extracted with two phenylamide groups. Secondly, from the FT-IR spectroscopy, there are unreacted phenylamide groups after silver loading. Thirdly, from the CPK model of the secondary phenylamide trident molecule, it is difficult to envisage a structure where all three phenylamide groups face inward toward the tripodal site. For these reasons, the secondary phenylamide trident molecule has been proposed as a bidentate ligand. In the case of the phenylamide type of the monopodal molecule, two extraction reagent molecules extract silver as a cation with a counter anion by a direct coordination mechanism. The trident molecule contains an uncoordinated functional group during silver complexation compared with the monopodal molecule. It provides, however, a partially convergence of the functional groups and consequently exhibits a high extraction ability as shown in Figure 3.

(a)
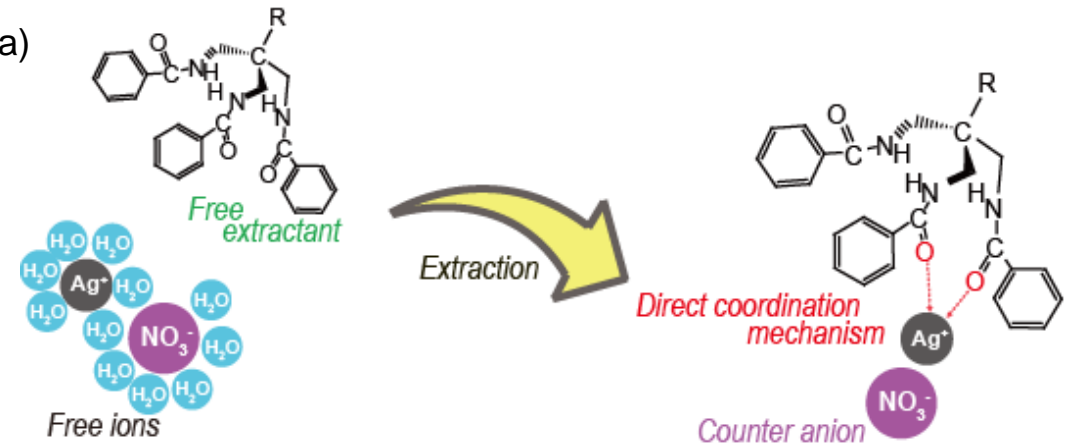

(b)
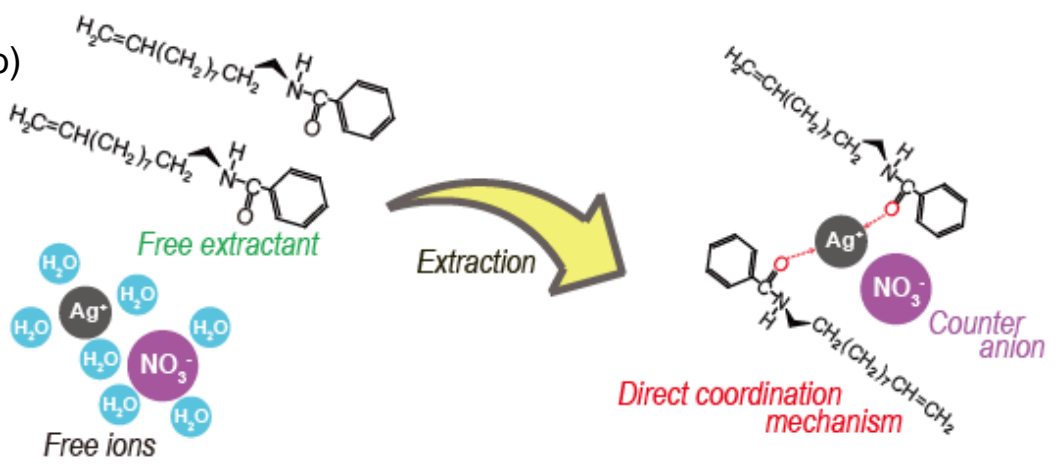

Figure 7. Proposed extraction model for silver with the secondary phenylamide type of (a) the trident and (b) the corresponding monopodal extraction reagents in nitrate media. 


\subsection{Extraction of other metals}

The effects of nitric acid concentration on the extraction percentages of other metals with the secondary phenylamide trident molecule are shown in Figure 8. Divalent palladium was significantly extracted at low nitric acid concentration and the extraction percentage decreased with increasing nitric acid concentration. Tetravalent platinum, trivalent ruthenium, trivalent rhodium and base metals, such as trivalent iron, divalent cobalt, divalent nickel, divalent copper and divalent zinc were hardly extracted at all at any concentration of nitric acid. Such precious and base metals exist as cationic species in nitrate media. For the extraction of cationic species with a neutral ligand, counter anions are necessary for neutralization, consequently it is difficult to extract multivalent cationic species. However, it is reported that divalent palladium exists as $\mathrm{PdNO}_{3}{ }^{+}$or $\mathrm{Pd}\left(\mathrm{NO}_{3}\right)_{3}{ }^{-}$species in high concentrations of nitric acid [22]. The secondary phenylamide type of tridentate molecule extracted both silver and divalent palladium.

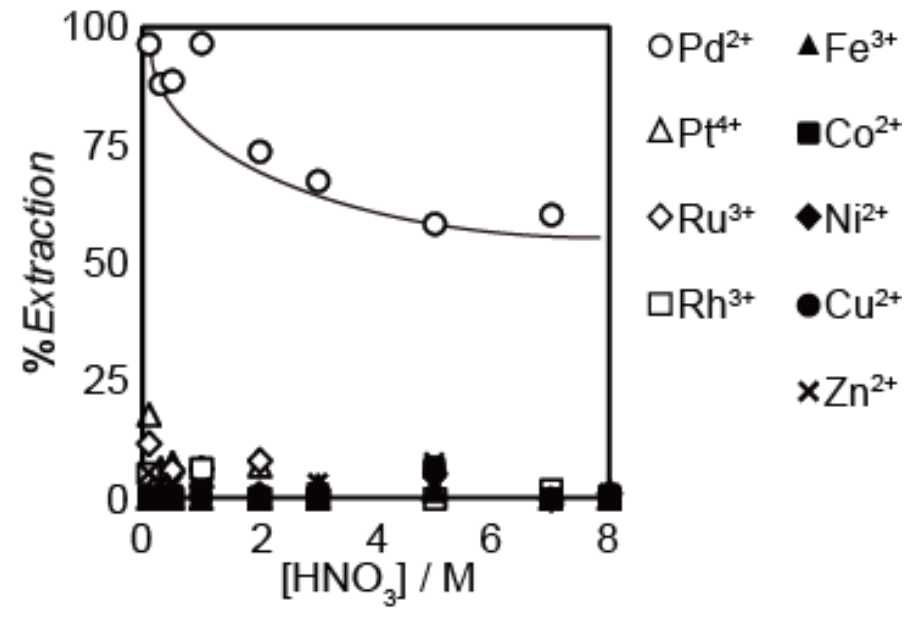

Figure 8. Effects of nitric acid concentration on the extraction percentage of other metals with the secondary phenylamide type of trident extraction reagent. [Metal ions] $=0.1 \mathrm{mM}$, $\left[{ }^{8} \mathrm{Nonenyl}\{3\} \mathrm{CH}_{2} \mathrm{NHC}(\mathrm{O}) \mathrm{Ph}\right]=5.0 \mathrm{mM}$.

\section{Conclusions}

The secondary phenylamide derivative of a trident molecule together with the corresponding monopodal molecule has been prepared from the primary amino derivative of the trident molecule by the Schotten-Baumann reaction. The extraction ability for silver with the trident molecule from nitric acid solution was superior to that of the monopodal analogue due to converging effects. The stoichiometry of the complex foemed between silver and the trident extractant was determined to be $1: 1$ (extractant : metal) using slope analysis. The recognition site for monovalent silver with the trident molecule was determined to be outside of the trident extractant as suggested by FT-IR and ${ }^{1} \mathrm{H}-\mathrm{NMR}$ spectra. The selective extraction of silver and divalent palladium from other precious and base metals has been achieved. 


\section{Acknowledgement}

This work was financially supported in part by a VA-related Polymers Research Laboratory, Kurashiki Research Center, Kuraray Co. Ltd.

\section{References}

1) J. T. Kummer, Prog. Energy Combust. Sci., 6, 177-199 (1980).

2) J. Wei, E. Iglesia, J. Catal., 225, 116-127 (2004).

3) B. J. Glaister, G. M. Mudd, Miner. Eng., 23, 438-450 (2010).

4) E. Benguerel, G. P. Demopoulos, G. B. Harris, Hydrometallurgy, 40, 135-152 (1996).

5) K. Ohto, E. Murakami, T. Shinohara, K. Shiratsuchi, K. Inoue, M. Iwasaki, Anal. Chim. Acta., 341, 275-283 (1997).

6) K. Ohto, Solvent Extr. Res. Dev., Jpn., 17, 1-18 (2010).

7) T. Yoneyama, K. Ohto, H. Harada, H. Kawakita, Solvent Extr. Res. Dev., Jpn., 17, 187-194 (2010).

8) B. B. Adhikari, M. Gurung, H. Kawakita, K. Ohto, Analyst, 136(21), 341-353 (2011).

9) B. B. Adhikari, M. Gurung, H. Kawakita, K. Ohto, Analyst, 136(18), 3758-3759 (2011).

10) B. B. Adhikari, M. Gurung, H. Kawakita, K. Ohto, Analyst, 136(21), 4570-4579 (2011).

11) B. B. Adhikari, M. Gurung, H. Kawakita, Jumina, K. Ohto, J. Hazard. Mater., 193, 200-208 (2011).

12) B. B. Adhikari, M. Gurung, H. Kawakita, K. Ohto, J. Inclusion Phenom. Macrocycl. Chem., 71(3-4), 479-487 (2011).

13) K. Ohto, Bunseki Kagaku, 61(3), 157-167 (2012).

14) B. B. Adhikari, M. Gurung, H. Kawakita, K. Ohto, Chem. Eng. Sci., 78, 144-154 (2012).

15) M. Kawashima, H. Kawakita, K. Ohto, Y. Shiwa, Solvent Extr. Res. Dev., Jpn., 19, 41-50 (2012).

16) K. Ohto, H. Nakagawa, H. Furutsuka, T. Shinohara, T. Nakamura, T. Oshima, K. Inoue, Solvent Extr. Res. Dev., Jpn., 11, 121-134 (2004).

17) H. Furugou, K. Ohto, H. Kawakita, H. Harada, K. Inoue, Ars. Sep. Acta, 5, 68-75 (2007).

18) R. Yamaguma, A. Yamashita, H. Kawakita, T. Miyajima, C. Takemura, K. Ohto, N. Iwachido, Sep. Sci. Technol., 47(9), 1303-1309 (2012).

19) N. Busschaert, P. A. Gale, C. J. E. Haynes, M. E. Light, S. J. Moore, C. C. Tong, J. T. Davis, W. A. Harrell, Jr., Chem. Commun., 46, 6252-6254 (2010).

20) H. Yamamoto, S. Saito, Pure Appl. Chem., 71(2) 239-245 (1999).

21) M. Yasuda, S. Yoshioka, S. Yamasaki, T. Somyo, K. Chiba, A. Baba, Org. Lett., 8(4), 761-764 (2006).

22) H. Nakajima, M. Yasuda, K. Chiba, A. Baba, Chem. Commun., 46, 4794-4796 (2010).

23) H. Nakajima, M. Yasuda, R. Takeda, A. Baba, Angew. Chem. Int. Ed., 51, 3867-3870 (2012).

24) R. J. Warr, A. N. Westra, K. J. Bell, J. Chartres, R. Ellis, C. Tong, T. G. Simmance, A. Gadzhieva, A. J. Blake, P. A. Tasker, M. Schroder, Chem. Eur. J., 15, 4836-4850 (2009).

25) C. Yamamoto, H. Hirokazu, K. Ohto, H. Kawakita, H. Harada, Anal. Sci., 27(4), 389-393 (2011). 
26) K. Ohto, H. Yamaga, E. Murakami, K. Inoue, Talanta, 44, 1123-1130 (1997).

27) H. Narita, M. Tanaka, K. Morisaku, T. Abe, Hydrometallurgy, 81, 153-158 (2006).

28) O. Clement, B. M. Rapko, B. P. Hay, Coord. Chem. Rev., 170, 203-243 (1998).

29) T. Fujii, H. Yamana, M. Watanabe, H. Moriyama, J. Radioanal. Nucl. Chem., 247(2), 435-437 (2001).

30) T. Nakamura, K. Ohto, T. Oshima, K. Inoue, Ars Sep. Acta., 4, 27-36 (2007).

31) Y. Baba, Y. Umezaki, K. Inoue, J. Chem. Eng., Jpn., 19(1), 27-30 (1986).

32) FZ EI Aamrani, A. Kumar, L. Beyer, M. Petrich, AM Sastre, J. Chem. Technol. Biotechnol., 75, 701-706 (2000). 